\title{
HUMBOLDT E O IDEALISMO DA ÉPOCA
}

\author{
Sebastião Elias Milani
}

\begin{abstract}
Resumo: Idealista, Humboldt enunciou no conteúdo de sua obra a essência do pensamento de seu tempo no tocante aos estudos da linguagem e da política. Era um homem estudioso das idéias de seu tempo; foi, portanto, em sua época, um moderno. São conceitos humboldtianos para a língua: o homem vê o mundo do modo como sua língua lhe apresenta esse mundo; e a língua e o pensamento do indivíduo são partes de um conjunto: a língua que o indivíduo fala, o ajuda pensar $e$, conforme ele pensa, mais perfeita fica sua língua. Como era típico entre os pensadores da Gramática Comparada, pesquisou a origem da linguagem humana; da mesma forma que atrela a língua ao espírito da nação.
\end{abstract}

Palavras-chave: linguística, filosofia da linguagem, Gramática Comparada

\section{Introdução}

O objetivo deste artigo é mostrar o indivíduo/cientista Wilhelm von Humboldt (1767-1835) como produto do movimento de idéias em que viveu. Em outras palavras: Humboldt conceituou a língua e a linguagem do modo como o fez porque era parte de um movimento, como o são também outros estudiosos da linguagem do mesmo período. Se, em seus escritos, Humboldt se mostra extremamente filosófico, é porque em seu mundo e em seu momento histórico tudo estava completamente permeado por conceitos filosóficos: antes de qualquer outro estudo, os cientistas desse período estudavam os filósofos. Quer-se afirmar que Humboldt fez pesquisas em linguagem segundo o movimento intelectual que participava.

Esse conjunto de elementos culturais veio a ser chamado, na arte, de Romantismo; esse é um movimento de idéias estéticas que abrange todas as vertentes artísticas e científicas, ou de outra natureza, que façam parte dessa época. É por ser tão abrangente que sua definição é tão complexa. Não se deve, entretanto, parar por estes termos. Importante pensar no Romantismo como marca da mudança de atitude do homem em relação ao homem e, desde esse movimento estético-filosófico, não houve outra mudança de comportamento tão significativa. Por isso, muitos teóricos afirmam que ainda se está vivendo a época romântica; moderna, como é nominada entre os prussianos. Outros, ainda, afirmam que somente acontecerá outra mudança tão significativa quando o homem se

\footnotetext{
* Professor Doutor da Faculdade de Letras da Universidade Federal de Goiás - UFG.
} 
tornar espacial, ou seja: a época romântica somente será substituída pela época espacial, que ainda não se iniciou. ${ }^{1}$

Na virada do século XVIII para o XIX, a Europa se deparou com momentos de transformação total. Das idéias ilustradas do século XVIII às modernidades românticas do século XIX, conta-se um grande número de gênios criados pela arte do pensamento. Wilhelm von Humboldt nasceu em Potsdam em 1767 e morreu em Tegel em 1835. Entre os eventos importantes que participou estão a Revolução Francesa de 1789 e as guerras napoleônicas, as guerras franco-prussianas e outras guerras. Participou da elaboração de uma constituição do governo prussiano e da fundação de várias Universidades. Entre elas está a Universidade Livre de Berlim, cujo primeiro estatuto é de sua autoria. Sua obra pode ser dividida em duas fases: até 1818, quando deixa a vida política, e a partir de 1818, período que se dedicou totalmente aos estudos sobre linguagem.

Idealista, Humboldt coloca no conteúdo de sua obra a essência ideológica do pensamento de seu tempo. Na primeira fase de sua obra, período em que se dedicou à política, principalmente à política de relações exteriores, expressa o desejo de liberdade e modernidade que caracterizou os movimentos libertários pós-Revolução Francesa. Os escritos políticos que redigiu, sobretudo entre 1793 e 1800, são marcados por idéias de um Estado menos autoritário e um cidadão mais livre e protegido.

A Prússia, bem como outros países da Europa, tinha duas classe sociais distintas: uma classe aristocrática, a que pertenciam os filósofos, e a outra, a classe dos cidadãos comuns, que viviam miseravelmente. Elenca-se uma gama de fatos sociais e artísticos que demonstram a insatisfação geral em relação a essas políticas. Da Revolução Francesa brotaram as idéias de um Estado mais democrático. Na poesia, contam-se muitos escritores revelando esse mal viver: Schiller e Goëthe faziam grandes inovações; Victor Hugo e Patrik Süskind, entre outros, protestavam por meio de seus romances. Sobre a linguagem, existiam o Racionalismo de Christian Wolff, os discursos sobre a razão de Immanuel Kant e as idéias de Herder, que muito influenciaram as pesquisas que Humboldt desenvolveria nos últimos vinte anos de sua vida.

Do Oriente chegava a filosofia indiana, contida nos textos em sânscrito, traduzidos para o inglês por William Jones. O sânscrito era uma língua indo-européia e seu conhecimento ajudava os ocidentais a retrocederem em seu passado. A filosofia indiana, aparentemente monoteísta, corroborava as idéias dos românticos. Em um resumo grotesco: "o homem era mesmo divino e era criador de si mesmo; Deus existia, mas era apenas Deus; o homem era, enfim, dono de seu destino".

O sânscrito era a prova de que havia um passado desconhecido, anterior às nações européias e médio-orientais antigas. Afastava mais para o passado a interferência de Deus como o criador das línguas e reafirmava o homem como centro de seu destino. Isso cabia perfeitamente nos ideais românticos, despertando o que René Gérard (1963) chamaria de "orientalomania romântica" - uma quase que obrigatoriedade, entre os estudiosos da

\footnotetext{
${ }^{1}$ Cabe lembrar que os movimentos de idéias, posteriores a qualquer movimento, fizeram ou fazem o que querem com as idéias construídas no passado. Esse passado, porém, não deve ser estigmatizado por isso. Especificamente, o que o Nacional-socialismo fez com as idéias dos românticos, tenham sido elas quais forem, é de responsabilidade do Nacional-socialismo. Não se trata, então, de estigmatizar ou rejeitar as idéias do Romantismo alemão como criadoras do Mal, porque elas não criaram o Mal: na verdade, o Mal é que se serviu delas. Evitá-las, ou bani-las do convívio contemporâneo, não serviria para evitar o Mal, pelas más interpretações.
} 
linguagem do período, de se especializarem no conhecimento da língua e da filosofia indianas e, até mesmo, chinesas.

A história da Índia antiga levava os ocidentais a um passado até então nunca alcançado, desfazendo dogmas sobre a origem dos ocidentais, que ainda acreditavam na existência de uma língua originária divina. Humboldt questionou esses dogmas. Argumenta ser improvável a descoberta de uma língua originária e que, provavelmente, as línguas da antigüidade clássica teriam uma origem semelhante às línguas neo-latinas.

A obra de Humboldt está permeada pela filosofia indiana. Era um homem envolvido nos assuntos de seu tempo; foi, portanto, um moderno. Seu trabalho está plenamente marcado pelos assuntos centrais dessa época, e a filosofia indiana era um desses assuntos. $\mathrm{O}$ sânscrito foi apresentado em sua obra como o espécime lingüístico a ser observado e "imitado": essa é a língua que, para ele, revela do melhor modo o mundo para o homem e a que melhor o ajuda a pensar.

Nas afirmações acima estão dois dos conceitos humboldtianos para a língua: o homem vê o mundo do modo como sua língua lhe apresenta esse mundo; e a língua e o pensamento do indivíduo são partes de um conjunto: a língua que o indivíduo fala o ajuda a pensar e, conforme ele pensa, mais perfeita fica sua língua.

Humboldt e muitos outros Comparatistas estudaram a tipologia das línguas. Em Humboldt fica bastante claro que seu objetivo básico, ao fazê-lo, não era estabelecer uma tipologia classificatória ou hierarquizante para elas. Mas, fosse essa tipologia qual fosse, trabalhou com a diferença de formalização entre as línguas para estabelecer o comportamento delas, chegando a estabelecer, na seqüência de sua reflexão, modelos lingüísticos - mas descobre que esses modelos muito dificilmente acontecem totalmente nas línguas. Segundo Humboldt, portanto, cada uma possui um tipo individual, único, que se resume em sua fórmula formal.

Esses modelos seriam o flexional, o aglutinante e o isolante. Eles têm como espécimes lingüísticos modelares o sânscrito para o flexional e o chinês para o isolante. $\mathrm{O}$ modelo aglutinante, segundo Humboldt, também se constitui num tipo de flexão, porém, menos perfeito que o flexional. Em muitos casos, as aglutinações podem ter sido a origem do modelo flexional de uma língua, mas isto é muito difícil de ser provado. Na verdade, na humanidade existem dois tipos ou sistemas lingüísticos, que se colocam com total distinção: o flexional e o isolante.

No primeiro, juntam-se, do modo mais "amarrado" possível, os conceitos uns aos outros, o que acarreta o desenvolvimento de conceitos mais complexos e profundos. $\mathrm{O}$ sânscrito, língua da Índia antiga, é a língua que melhor conseguiu realizar este intento formal. O sânscrito seria, então, o modelo flexional, mais bem acabado, dentre os modelos flexionais conhecidos.

O segundo, o isolante, tem como língua modelar o chinês. Ele se caracteriza por separar os sentidos em formas que são sempre distintas, que jamais se juntam. Nesse modelo, então, todas as formas se comportam como se fossem um radical. Humboldt, na verdade, apresenta o chinês como modelo único de seu espécime: é a única língua conhecida que se realiza como discurso isolando formas.

Segundo Humboldt, então, existem dois modelos lingüísticos que se colocam nos extremos da tipologia. Ambos são perfeitos porque não misturam em sua fórmula nada que não tenha sua forma, ou que proceda de uma outra fórmula. Isso não significa, nos termos humboldtianos, que o chinês e o sânscrito sejam línguas absolutamente perfeitas. São elas, todavia, aquelas que mais se aproximam dessa perfeição modelar, porque abandonam 
qualquer mistura, ou qualquer forma, cuja origem não pertença à escolhida pela língua em sua origem.

Esses sistemas lingüísticos estão nos extremos, e ambos são, segundo os termos de Humboldt, perfeitos; todos os outros sistemas lingüísticos, inclusive o aglutinante e o incorporador (polissintético), estariam colocados em um ponto qualquer entre eles. Porém, nenhum modelo é imperfeito: todos são perfeitos na medida em que realizam com perfeição o intento lingüístico de uma nação, ou seja, na medida em que revelam o espírito-nacional de um povo. Desse modo, "perfeito" quer dizer o que melhor apresenta o pensamento da nação; em decorrência, "perfeito" também é aquele que mais ajuda o indivíduo a pensar, é aquele em que suas formas, através do exercício intelectual, se cristalizaram e estão completamente afinadas com o pensamento. Enfim, "perfeito" é o modelo que apresenta formas completamente abstraídas de qualquer materialidade, deixando o indivíduo completamente livre para criar por meio do pensamento abstrato: nos termos de Humboldt, "criar-pensando".

Perfeito, nesses casos, não é oposição a imperfeito. Nenhuma língua é imperfeita. Ao contrário, todas são perfeitas. Elas apresentam a fórmula exata que seu povo falante tem como capacidade de abstração intelectual e, quanto mais perfeito for o pensamento abstrato, ou seja, o uso da inteligência por um povo, melhores recursos sua língua terá para ajudá-lo a pensar. É o pensamento do povo que aperfeiçoa a forma da língua, e a língua do povo favorece o desenvolvimento das idéias na medida da capacidade de língua que os indivíduos têm de produzir linguagem. Então, quanto mais o indivíduo pensa, melhores recursos ele tem para pensar, uma vez que o pensamento se realiza em forma de língua (ou linguagem). Conseqüentemente, do desenvolvimento do pensamento ocorre o desenvolvimento da língua, que, por sua vez, se coloca à disposição do pensamento para que ele se desenvolva.

Quanto mais uma língua desenvolve suas formas sempre na mesma direção, mais próxima de uma suposta perfeição lingüística vai estar. Isso não significa que ela vai estar mais próxima de um dos extremos lingüísticos: vai estar mais próxima de alcançar sua perfeição lingüística, sua perfeição como língua daquele povo. Isso significa que seus falantes estarão falando uma língua mais perfeita. Estarão, na verdade, pensando com perfeição. Então, sânscrito e chinês são extremos lingüísticos não como posição hierarquizada no espaço-tempo, mas como símbolos de perfeição em si mesmos.

Não se poderia deixar de falar na importância que Humboldt atribui ao ensino da língua materna para o povo: quanto mais culto, ou melhor, quanto mais e bem o povo souber sua língua, mais capaz de criar-pensando ele será. O desenvolvimento da língua, entre outras coisas, leva até os indivíduos o conhecimento dos detalhes culturais que compõem seu mundo e o mundo de todas as pessoas. Isso quer dizer não só conhecer, mas também entender e refazer aquilo que no contexto social não estiver bom - o que, pelo menos em tese, é verdadeiro.

Humboldt propunha que o indivíduo que conhece melhor a língua que fala se expressa melhor; e, como o pensamento funciona por meio da língua, o indivíduo pensa melhor quanto melhor for a língua que fala. É certo que, quanto mais o indivíduo estuda sua língua, mais recursos seu pensamento tem para se desenvolver e desenvolver a própria língua. Isso vai além desse círculo, quando se pensa que tudo que se materializa no universo das coisas foi primeiramente materializado em forma de linguagem: o pensamento elabora uma idéia em forma de linguagem, e para esse processo de ideação basta um único indivíduo; no momento, porém, em que ela já esteja formalizada como linguagem, outros indivíduos têm acesso a ela, tornando possível que essa idéia se transforme num objeto 
material, na dependência apenas do fato de esse objeto ser ou não materializável com matéria não-lingüística.

Conclui-se, desse modo, que os indivíduos falam uma língua individual que se "encaixa" na língua de muitos grupos e que, acima de tudo, se "encaixa" na línguanacional. E a nação é, por definição, o grupo que melhor classifica os indivíduos.

Humboldt define os indivíduos como participantes da nação. É pelo amor à Pátria e pela identificação lingüística que os indivíduos se agrupam. Então, o único grupo, realmente definido, de que o indivíduo participa, é a nação. Nenhum grupo pode existir sem que exista uma conformidade entre suas regras e as leis da nação em que ele esteja inserido.

Se forem estudadas duas nações com línguas que tenham a mesma origem - por exemplo, as nações de língua portuguesa -, não se pode dizer que elas tenham a mesma língua-nacional. Segundo Humboldt, as línguas refletem o contexto em que estão inseridas: o conjunto de fatores socioculturais, sócio-econômicos, geo-históricos etc., que varia muito de uma nação para outra, varia também dentro de uma mesma nação; varia, inclusive, de indivíduo para indivíduo, por mais próximas que sejam suas experiências de vida. Então, como acontece o fenômeno da comunicação entre os indivíduos?

A nação é um grupo coeso de interesses. Todos os indivíduos que participam de qualquer uma de suas partes estarão interessados em assuntos nacionais que dizem respeito a todos. Esse conjunto de interesses é regido principalmente pelo amor à Pátria e estabelecido basicamente pela língua-nacional. Em qualquer parte da nação em que o indivíduo habite, ele se sentirá irmão de qualquer indivíduo que habite em qualquer outra parte da nação. Os indivíduos, dentro de uma nação, vivem, muitas vezes, muito mais distanciados espacialmente do que em relação a indivíduos de outras nações. Em geral, nas fronteiras entre países, o que separa indivíduos são linhas muitas vezes imaginárias.

No entanto, nas idéias de Humboldt, a distância espacial nada significa quando se trata do amor à Pátria. Esse fenômeno da identificação ou do afastamento entre os indivíduos se estabelece através da língua, único armazém cultural que os seres humanos possuem. A língua reflete tudo aquilo que a nação é, foi ou será. Ela, somente ela, é que torna a nação possível: não poderia existir uma nação sem uma língua-nacional, porque a língua reflete o espírito do povo e o espírito do povo está inteiramente espalhado pela língua: são a mesma coisa; quando ocorrer uma mudança qualquer, em qualquer parte do espírito do povo, a língua imediatamente a assimilará, porque nada é pensável se não for pela língua. Então, por meio da língua se cria o espírito-nacional; ele possibilita a existência dela. Sendo a língua o reflexo do espírito-nacional, ela é parte integrante e inalienável dele, porém ele só é possível através dela.

Desse modo, dentro de uma nação, mesmo que se formem milhares de grupos, esses grupos só existiram se o espírito-nacional, do qual esses grupos fazem parte, os aceitar. Qualquer elemento que for destoante com os elementos aceitos como regra nacionalmente, tenderá a ser eliminado. Então, qualquer grupo que exista na nação fala a língua da nação; qualquer indivíduo, cidadão dessa nação, poderá fazer parte desse grupo, ou melhor, qualquer indivíduo falante da língua-nacional, ou seja, conhecedor do espírito-nacional, do ponto de vista da língua poderá fazer parte de qualquer grupo da nação.

Por isso, dentro de uma nação, grupos considerados completamente diferentes estão mais próximos entre si do que entre grupos semelhantes de nações diferentes. O espíritonacional é que possibilita qualquer integração entre os indivíduos, e o espírito-nacional é eminentemente linguagem. É, então, através da língua, que se estabelece a interação entre os indivíduos: línguas diferentes dificultam ou mesmo impedem essa interação. Desse modo, para que um indivíduo se integre em uma nação, ele precisa antes de tudo saber a 
língua-nacional daquele povo. Portanto, aprender uma língua estrangeira é adquirir a fórmula do espírito-nacional elaborado pelo pensamento de um povo.

Dentro da nação, como se disse acima, milhares de grupos se instalam, todos eles cooparticipantes de um todo. Cada grupo, porém, independentemente do número de indivíduos que o integram, fala uma língua específica, grupal. Prosseguindo nesse raciocínio, cada indivíduo que compõe uma nação fala uma língua que é só sua, que varia e se transforma cada vez que ele se integra ou se desintegra de um grupo. Ele jamais deixará, entretanto, de estar integrado à nação. Desse modo, em qualquer lugar da nação em que esteja, estará falando a mesma língua.

A língua, no entanto, só existe em forma de discurso - que só acontece quando um indivíduo coloca a língua em movimento. O discurso, por sua vez, é produção do pensamento, que é um recurso exclusivo dos indivíduos. A língua-nacional e o espíritonacional, portanto, só existem no pensamento dos indivíduos. O que se dá como logicamente estabelecido, porque o objeto não existe sem os indivíduos, e o espíritonacional se compõe de objetos.

Por esse prisma, a perfeição lingüística numa nação está intimamente relacionada com o pensamento dos indivíduos. Assim, o desenvolvimento intelectual, através da escola, é fundamental para o desenvolvimento da nação. Se o povo apresenta uma qualidade intelectual de alto nível, isso significa que o povo pensa e se expressa de modo satisfatório. Provavelmente, em um tal contexto, a escola não só seja acessível a todos ou à maioria, como também bastante eficiente. Humboldt disse: se se pensar que, numa tal nação, o pensamento abstrato tenha atingido alto nível, ter-se-ia chegado, então, a um ideal e a nação que alcançou tal meta seria superior às outras. Humboldt disse isso, os românticos disseram isso, ou de forma parecida. Humboldt e os românticos desejavam que o mundo fosse a concretização de um ideal.

Humboldt escreveu que o sânscrito era e permaneceu mais perfeito. Os falantes de sânscrito, que já formavam um grupo selecionado, estudavam e se esforçavam para mantêlo isento de interferências estrangeiras e para bem pronunciá-lo. Segundo Humboldt, os indianos tinham razão em seu esforço, porque quanto mais pura e mais bem pronunciada for a língua, mais bonita e mais perfeita ela será, não sofrendo jamais qualquer deformação - ao mesmo tempo em que, com o exercício de bem falar que os indianos praticavam, a língua se tornava cristalizada e ajudava de modo mais positivo seus falantes em seus exercícios de pensar.

Se o sânscrito era uma língua perfeita e seus falantes se esforçavam para mantê-la sempre assim; esse esforço era coroado, segundo Humboldt, pelo sistema lingüístico flexional que o sânscrito adota. Humboldt escreveu que, dentre os sistemas linguísticos, aquele que se mostra ideal é o flexional. Nesse sistema, como já foi dito, os sentidos são lapidados e se formam pela junção de formas que têm uma função exclusiva: aquela que exercem, desfazendo, assim, qualquer possibilidade de ambigüidade não desejada, deixando o pensamento inteiramente livre para criar os contornos que desejar.

Numa língua em que a perfeição lingüística tenha alcançado um nível bastante elevado, as formas possuem precisão e abstração e o pensamento desliza livremente por elas sem enfrentar qualquer dureza de formas não cristalizadas. Por outro lado, uma língua não tão aperfeiçoada obrigará seu falante a abandonar os conceitos abstrato e teórico e se fixar no prático e no concreto, contentando-se com eles, limitando enorme e negativamente sua inteligência e a precisão de seus pensamentos.

Esse aperfeiçoamento não ocorre somente com espíritos-nacionais. Quando um indivíduo é intelectualizado, sua língua se aperfeiçoa, seu pensamento funciona de modo 
eficiente, e ele usará e expressará sua criatividade de modo muito mais eficiente, ajudando infinitamente mais sua nação. É nesses moldes e com esses objetivos que Humboldt prega o ensino da língua materna para o povo.

Esse pensamento não foi somente para o exercício da linguagem. Fica evidente que nessas idéias estão presentes os ideais políticos e sociais de Humboldt enquanto homem público e indivíduo interessado nas causas da cidadania. Essas idéias foram desenvolvidas por Humboldt, mas estavam no centro do pensamento romântico prussiano. Eram resultantes do conjunto de elementos que se agrupavam no contexto em questão: os ideais revolucionários, a filosofia indiana, o conceito do homem como fonte e conhecedor de seu destino, o desejo de renovação que tornava o Romantismo sinônimo de modernidade, etc. Humboldt não foi o único que as sintetizou em sua obra. Em geral, todos os românticos fazem algo semelhante. Esse agrupamento que gera um movimento sociotemporal de idéias cria um espírito que reestrutura a língua, que se caracteriza e vira símbolo de um tempo. A esse movimento sociotemporal Humboldt chamou de geração.

Se por um lado, como foi dito acima, os indivíduos se agrupam lingüisticamente de modo espacial (a nação), ou, de outra maneira, de modo temporal (as gerações), isso demonstra que qualquer estrutura social funciona por ciclos: os indivíduos se renovam e se modificam, e os grupos só sobrevivem ao tempo se se adaptarem, ou seja, se se tornarem novos a cada geração. Do ponto de vista da nação isso é uma lei: a cada período tudo se renova, o espírito-nacional se modifica e a língua com ele.

As gerações são períodos que não têm tempo exato de duração. São marcados por eventos de qualquer natureza que sacodem as sociedades num determinado ponto. Em geral, esses eventos ocorrem a todo instante e seus efeitos e proporções são mensuráveis de acordo com o número de indivíduos que são abalados.

Eventos históricos que tenham causado modificações na humanidade inteira foram a Revolução Francesa, a Revolução Industrial, a chegada do homem à Lua, as grandes guerras - que foram, todos, eventos de massa. Indivíduos, porém, com suas idéias podem modificar os contornos dos pensamentos do mundo inteiro, tanto de forma positiva como negativa, como por exemplo Napoleão, Hitler, Isaac Newton, Jesus Cristo, Maomé, Buda, cantores de rock, etc. - todos, mas cada um em suas proporções, usaram a palavra para realizar seu intento.

Movimentos culturais surgem de uma atitude individual ou coletiva em algum lugar e, de acordo com sua aceitação, se espalham por todas ou algumas partes da humanidade. Os românticos eram filósofos, como qualquer indivíduo que produza linguagem o é. A língua é filosófica sempre, ou melhor, o conhecimento é filosófico; portanto, o signo é filosófico. Alguns estudiosos chamam o signo de ideológico - mas cabe lembrar, entretanto, que ideologia é, também, um conceito da filosofia. Os românticos estudaram a linguagem como formadora de conceitos: a língua é, portanto, um conceito. Os românticos faziam filosofia: aqueles, dentre eles, que estudavam as línguas eram filósofos da linguagem. Formam uma geração, porque modificaram o pensamento mundial e as línguas em geral.

A língua, portanto, é construtora de idéias, é portadora de idéias. O pensamento dela se serve para existir e a transforma segundo sua necessidade. A língua como movimento coletivo, nacional, envolve e engloba a produção do pensamento, que é sempre individual. Em qualquer tempo e lugar, a língua é a soma absoluta da história da nação na óptica do indivíduo que discursa.

Cabe uma última asserção sobre o conceito de língua na obra de Humboldt. Ele faz perceber que o discurso é a forma materializada da língua; é produção individual que se assemelha ao todo. Deixa claro o estudioso que a produção discursiva do indivíduo resulta 
de suas experiências passadas, que estão registradas, no nível geral, no espírito-nacional, do qual os indivíduos tomam conhecimento pela língua; por outro lado, no plano individual, elas estariam registradas na memória dos indivíduos.

O discurso, então, é produzido pelo indivíduo segundo suas experiências passadas, que estariam registradas na língua. É segundo essa língua que o discurso se materializa. $\mathrm{O}$ indivíduo não tem consciência da língua: aquilo de que tem consciência é aquilo que se transformou em discurso. A língua, que é o espírito-nacional, estaria, por inferência, na inconsciência dos indivíduos, ou seja, em seu subconsciente. É, portanto, conforme esse inconsciente que o discurso é produzido. Nada novo, segundo a psicanálise, mas a psicanálise ainda não existia em 1835, quando Humboldt escreveu isso.

Humboldt deixa em sua obra marcas que fazem pensar na língua como algo além do palpável, além da matéria, em oposição ao discurso, que é matéria. Quando fala sobre o discurso poético, deixa claro para seu leitor atento que o poeta é alguém capaz de se conhecer e de conhecer o outro e de que, por isso, é capaz de revelar um discurso que não é o óbvio, que é a própria tradução do poeta.

\section{Conclusão}

Pode-se dizer, portanto, que Humboldt buscava uma explicação científica para aquilo que seus contemporâneos, artistas, descreviam em forma de poesia. Se o discurso é individual e revela o espírito do indivíduo e se a língua só existe em forma de discurso, a língua é então uma criação da mente dos indivíduos. Se criaram a língua, os indivíduos o fizeram por algum motivo; se o discurso revela o espírito dos indivíduos, ele revela e registra as necessidades individuais. Por conseguinte, a língua foi criada pelos indivíduos para que eles pudessem sair da própria mente: a língua é, na verdade, uma saída, uma válvula de escape para os indivíduos saírem de si mesmos.

Na mesma medida em que o discurso é a mente do indivíduo, seu pensamento é seu espírito. A nação representa um ser individual, formada por um espírito-nacional, pensável, desse modo, como um inconsciente coletivo - que, por sua vez, usa a língua-nacional como fórmula para sair de si mesmo.

O conceito de língua apresentado por Humboldt o coloca como produto e produtor do meio cultural em que viveu. Não só esse conceito, mas todos os outros conceitos de Humboldt o revelam como participante do movimento de idéias que caracterizou sua época. Humboldt fez tais afirmações porque são parte do movimento em que estava integrado. Em outras épocas, com toda certeza, elas são explicadas de outros modos. 


\section{Referências bibliográficas}

HumboldT; Wilhelm Karl von. Sobre la diversidad de la estrutura del lenguaje humano y su influencia sobre el desarrollo espiritual de la humanidad. Trad. e prólogo de Ana Agud.Barcelona: Anthropos, 1990.

Sobre el origem de las formas gramaticales y sobre su influencia en nel desarrollo de las ideas - Carta a M. Abel Rémusat sobre la naturaleza de las formas gramaticales en general y sobre el genio de la lengua china en particular. Trad. de Carmen Artal.Barcelona: Anagrama, 1972.

De l'origine des formes grammaticales et de leur influence sur le développement des idées. Paris: A. Franck, 1859. Traduction de Alfred Tonnellé.

1943.

Escritos políticos. Traducción de Wenceslao Roces.México: Fondo de cultura,

Humboldt; Wilhelm Karl von. Cuatro ensayos sobre España y América. Traducción de Miguel de Unamuno y Justo Garate.Buenos Aires: Espasa-Calpe, 1951.

.Estudios comparativos de las lenguas. Buenos Aires: Instituto de Filologia, s.d.

BAKHTin, Mikhail. Marxismo e filosofia da linguagem. São Paulo, Hucitec, 1995.

Benveniste, Émile. Problemas de lingüística Geral I e II. Trad. de Maria da Glória Novak e Maria Luisa Neri Campinas-SP, Pontes, 1995.

Coseriu, Eugenio. "Sulla tipologia linguistica di Wilhelm von Humboldt. Contributo alla critica della tradizione linguistica". Trad. de Giulia Cantarutti. Lingua e stilo 2 (1973) : 235265.

COSERIU, Eugenio. O homem e sua linguagem. Trad. de Carlos Alberto da Fonseca. Rio de Janeiro, Presença, 1993.

Ducrot, Oswald. Princípios de semântica lingüística. São Paulo, Cultrix, 1978.

Foucault, Michel. Arqueologia do saber. Trad. de Luiz F. B. Neves. Rio de Janeiro, Forense, 2002.

HJELMSLEV, Louis. Prolegômenos a uma teoria da linguagem. Paris, Minuit, 1943. Principes de grammaire générale. Paris, Minuit, 1928.

IlaRI, Rodolfo \& GERALDI, João Wanderley. Semântica. São Paulo, Ática, 1992. Coleção Princípios.

JAKOBSON, ROMAN. Lingüística e comunicação. Trad. de Izidoro Blikstein.São Paulo, Cultrix, 2000. JAKOBSON, Roman. Essais de linguistique générale. Trad. de Nicolas Ruwet.

Paris, Minuit, 1963.

KNOLL, Joachim H. Wilhelm von Humboldt: l'homme politique et le pédagogue. Internationes, 1967.

KRISTEVA, Julia. Essais de semiotique. Paris, Mouton, 1971. 
Abstract: Idealist, Humboldt declared in the content of his work the essence of the thinking of his time concerning the studies of language and politcs. He was a studious man of the ideas of his time; therefore, a modern in his age. Humboldtian concepts about language are: man sees the world through the way language presents this world to him; and the individual language and thought are part of a group: the language becames. As it was typical amongst thinkers of the Comparative Grammar, he researched the origin of human language; in the same way, he leases the language to the spirit of the nation.

Keywords: linguistics, philosophy of language, comparative grammar. 